\title{
Global transcriptome analysis of two wild relatives of peanut under drought and fungi infection
}

Patricia M Guimarães ${ }^{*}$, Ana CM Brasileiro ${ }^{1}$, Carolina V Morgante², Andressa CQ Martins³, Georgios Pappas ${ }^{1}$, Orzenil B Silva Jr' ${ }^{1}$, Roberto Togawaa ${ }^{1}$, Soraya CM Leal-Bertioli ${ }^{1}$, Ana CG Araujo ${ }^{1}$, Marcio C Moretzsohn ${ }^{1}$ and David J Bertioli,4

\begin{abstract}
Background: Cultivated peanut (Arachis hypogaea) is one of the most widely grown grain legumes in the world, being valued for its high protein and unsaturated oil contents. Worldwide, the major constraints to peanut production are drought and fungal diseases. Wild Arachis species, which are exclusively South American in origin, have high genetic diversity and have been selected during evolution in a range of environments and biotic stresses, constituting a rich source of allele diversity. Arachis stenosperma harbors resistances to a number of pests, including fungal diseases, whilst A. duranensis has shown improved tolerance to water limited stress. In this study, these species were used for the creation of an extensive databank of wild Arachis transcripts under stress which will constitute a rich source for gene discovery and molecular markers development.

Results: Transcriptome analysis of cDNA collections from A. stenosperma challenged with Cercosporidium personatum (Berk. and M.A. Curtis) Deighton, and A. duranensis submitted to gradual water limited stress was conducted using 454 GS FLX Titanium generating a total of $7.4 \times 10^{5}$ raw sequence reads covering $211 \mathrm{Mbp}$ of both genomes. High quality reads were assembled to 7,723 contigs for A. stenosperma and 12,792 for $A$. duranensis and functional annotation indicated that $95 \%$ of the contigs in both species could be appointed to $\mathrm{GO}$ annotation categories. A number of transcription factors families and defense related genes were identified in both species. Additionally, the expression of five A. stenosperma Resistance Gene Analogs (RGAs) and four retrotransposon (FIDEL-related) sequences were analyzed by qRT-PCR. This data set was used to design a total of 2,325 EST-SSRs, of which a subset of 584 amplified in both species and 214 were shown to be polymorphic using ePCR.

Conclusions: This study comprises one of the largest unigene dataset for wild Arachis species and will help to elucidate genes involved in responses to biological processes such as fungal diseases and water limited stress. Moreover, it will also facilitate basic and applied research on the genetics of peanut through the development of new molecular markers and the study of adaptive variation across the genus.
\end{abstract}

\section{Background}

Legumes are an important source of protein for humans and livestock. Cultivated peanut (Arachis hypogaea) is one of the most widely grown grain legumes in the world. It is widely cultivated mainly in Asia, Africa and the Americas, and is valued for its high protein and unsaturated oil contents [1,2]. Worldwide, the major

\footnotetext{
* Correspondence: messenbe@cenargen.embrapa.br

${ }^{1}$ EMBRAPA Recursos Genéticos e Biotecnologia. Parque Estação Biológica, CP 02372 Final W5 Norte, Brasília, DF, Brazil

Full list of author information is available at the end of the article
}

constraints to peanut production are drought and fungal diseases including Early (ELS) and Late Leaf Spots (LLS), the latter caused by Cercosporidium personatum [3-5].

Wild Arachis species, which are exclusively South American in origin, have high genetic diversity and have been selected during evolution in a range of environments and biotic stresses, and constitute a rich source of allele diversity [6-8]. The species A. stenosperma harbors resistances to a number of pests, including the root-knot nematode Meloidogyne spp. [9] and fungal diseases 
$[10,11]$, whilst $A$. duranensis is originated from regions with relatively low rainfall [12]. These wild relatives are a rich source of new alleles for peanut improvement as they have sufficient polymorphism for their genetic characterization, and the tracking of genome segments that confer these resistances during introgression into cultivated peanut [13-15]. Both species have been exploited as a resource for gene discovery, interpretation of genomic sequences and marker development [11,1519] and are also parents of a recently developed RIL (Recombinant Inbred Line) diploid mapping population.

In recent years, a relatively large number of EST sequences have been made available in the National Center for Biotechnology Information (NCBI) public database for $A$. hypogaea $(151,352)$. However, fewer resources exist for $A$. duranensis $(35,292)$ and $A$. stenosperma $(6,264)$. In addition, a whole genome sequencing project for peanut (tetraploid) remains a challenge, in part due to the size of the genomes compared to model plants, even for the diploid species (A. duranensis 1,260 Mbp vs. $115 \mathrm{Mbp}$ in Arabidopsis thaliana), but even more because of the high repetitive DNA content [20,21].

Functional genomics studies, using microarrays and subtractive libraries ( $\mathrm{SSH}$ ), identified genes potentially associated to stress responses to $C$. personatum and drought stress in Arachis spp. [3,4,22,23]. However, to our knowledge, no massal transcriptome analysis in stressed wild Arachis is available.

Increased transcriptome sequence resources should facilitate basic and applied research on genetics, contribute to the development of molecular markers, facilitate comparative genomics and aid in the study of adaptive variation across the genus. In addition, transcriptome data can assist on the elucidation of genes involved in biological processes, such as defense responses to biotic and abiotic stress, which Transcription Factors (TFs) are notably associated [24,25], and have hardly been studied in wild Arachis.

Although it is still a challenge to assemble a new whole complex genome using Next-Generation Sequencing technologies (NGS) (454/Illumina), the smaller size and reduced repetitive content of the transcriptome together with increased coverage facilitates the de novo transcriptome assembly using these technologies [26]. Next-generation sequencing technologies have facilitated large scale generation of ESTs cost-effectively, and allowed the whole transcriptome analysis of a number of smaller scale legume crops such as chickpea, lentil, mungbean and pigeonpea [27-30]. Moreover, deep sequencing has enabled the identification of new transcripts not present in previous model crops EST collections, such as Arabidopsis [31] and rice [32], and the massive identification of molecular markers such as SNPs (Single Nucleotide Polymorphisms) and SSRs (Simple Sequence Repeats) [33,34]. In addition, ESTSSRs being genic in origin, frequently display a high degree of transferability between related species.

In the present study 743,232 sequence reads were produced using Roche/454 GS FLX Titanium, generating a total of 17,912 unigenes for A. stenosperma and 21,714 for $A$. duranensis submitted to infection with $C$. personatum and gradual water limited stress, respectively. Contigs derived from these reads were annotated into functional categories separately for each species, and the expression of five Arachis RGAs (Resistance Gene Analogs) and four sequences related to the only fully-characterized Arachis retrotransposon (FIDEL) [20] further analyzed by qRTPCR (quantitative reverse transcription-PCR). This database was also used to design a set of 214 EST-SSRs primers which showed polymorphism via electronic PCR (ePCR) between the two species studied.

The genomic resources developed in this study can, in association with other tools already developed for wild Arachis, contribute to accelerate genetics and breeding of peanut and contribute particularly for the elucidation of genes involved in responses to important biological processes such as fungal diseases and water limited stress in peanut and other legumes.

\section{Results}

EST sequencing and assembly

A total of $7.4 \times 10^{5}$ raw sequence reads covering 211 Mbp were generated in a single 454 GS FLX Titanium run (Table 1) on the four libraries constructed from two

Table 1 Total number and length of 454 GS FLX Titanium reads for each library

\begin{tabular}{|c|c|c|c|c|}
\hline Libraries & Number of total reads & Total length (bp) & Number of high quality reads & High quality length (bp) \\
\hline A. stenosperma & 362,631 & $100,394,273$ & 310,430 & $85,649,830$ \\
\hline Asl & 194,076 & $51,609,348$ & 162,393 & $42,868,986$ \\
\hline AsC & 168,555 & $48,784,925$ & 148,037 & $42,780,844$ \\
\hline A. duranensis & 380,601 & $111,425,609$ & 276,884 & $78,147,055$ \\
\hline AdS & 200,031 & $60,268,742$ & 138,275 & $39,660,480$ \\
\hline $\mathrm{AdC}$ & 180,57 & $51,156,867$ & 138,609 & $38,486,575$ \\
\hline Total & 743,232 & $211,819,882$ & 587,314 & $163,796,885$ \\
\hline
\end{tabular}

I: inoculated with C. personatum; S: drought stressed; C: control. 
Arachis species subjected to biotic (A. stenosperma/C. personatum) and abiotic (A. duranensis/water limitation) stress and respective controls. After eliminating adapter sequences, low quality chromatograms and "masking" unwanted sequences (rDNA, mitochondrial, repetitive) a total of $3.1 \times 10^{5}$ processed high quality reads were obtained for A. stenosperma and $2.7 \times 10^{5}$ for A. duranensis (Table 1). The average length of high quality sequence reads was $278 \mathrm{bp}$ for A. stenosperma and $282 \mathrm{bp}$ for $A$. duranensis, enabling coverage of 85 and $78 \mathrm{Mbp}$ of the genomes, respectively (Figure 1, Table 1 ).

The high quality reads from the 454 GS FLX Titanium platform were then used for clustering and de novo assembly according to the genotype of origin, resulting in 17,912 unigenes (singletons and contigs) from A. stenosperma and 21,714 from $A$. duranensis (Table 2) with an average index of $83.8 \%$ of accepted reads for all the four libraries. The difference in the number of unigenes generated for the two species can be attributed to the fact that A. duranensis reads represent leaf and root transcriptomes, whilst $A$. stenosperma is solely composed from leaf tissues. The number of assembled unigenes found in this study including both species $(39,626)$ was comparable to those reported for other legumes such as pigeonpea [19,30], mungbean [29], lentil [27] and chickpea [28] also obtained using the 454 GS FLX Titanium platform.
After removing the singletons, we produced 7,723 high confidence consensus sequences (contigs) for A. stenosperma and 12,792 for $A$. duranensis, with each contig being built from, on average, a relatively high number of reads (33 for A. stenosperma and 19 for A. duranensis) (Table 2). The number of reads/contig and their length distribution are shown in Figure 2 (A and B). The majority of the contigs were assembled from 2 to 5 reads, with $90 \%$ of them containing less than 30 reads for both species (Figure 2). The average length of the contigs was 457 bp for A. stenosperma and 494 bp for A. duranensis, with $27 \%$ and $36 \%$ of them larger than 500 bp respectively (Figure 2).

The genome coverage of contigs from A. stenosperma was $8.18 \mathrm{Mbp}$ and $A$. duranensis 10.72 Mbp (Table 2), which make just under $1 \%$ of the estimated 1,260 Mbp size of a typical diploid Arachis species [35]. Sequence data from this study can be found for each species in the Sequence Read Archive (SRA) at the NCBI (A. duranensis - SRA047273.1; A. stenosperma - SRA047258.1). The derived contigs for each species and their most significant match against the $\mathrm{nr}$ database of GenBank ( $\mathrm{E}$ value $<\mathrm{e}-7$ ) is available in additional files (Additional files 1,2) and at NCBI in Transcriptome Shotgun Assembly (TSA) (A. duranensis - JR332677 -JR344253 and A. stenosperma - JR326556 - JR332676).
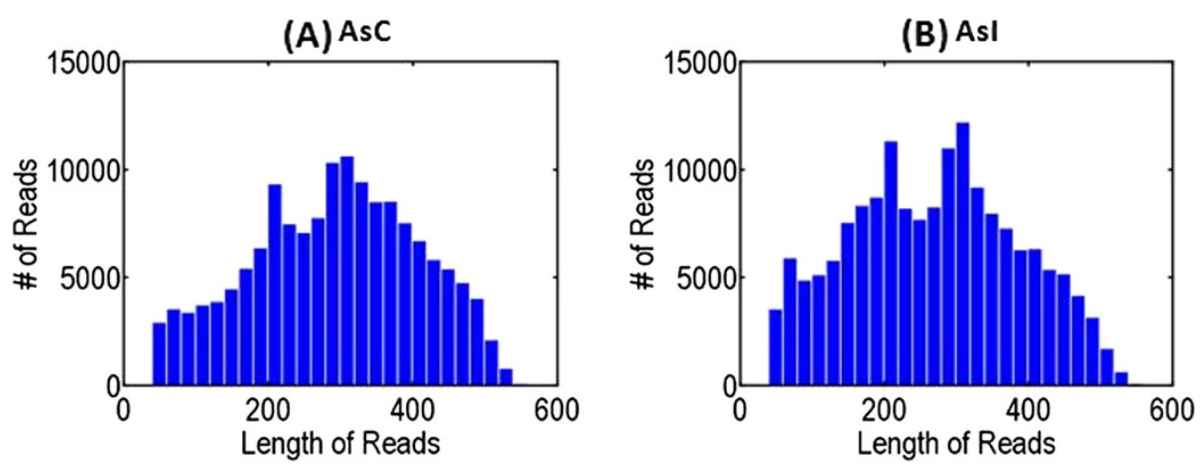

(C) AdC

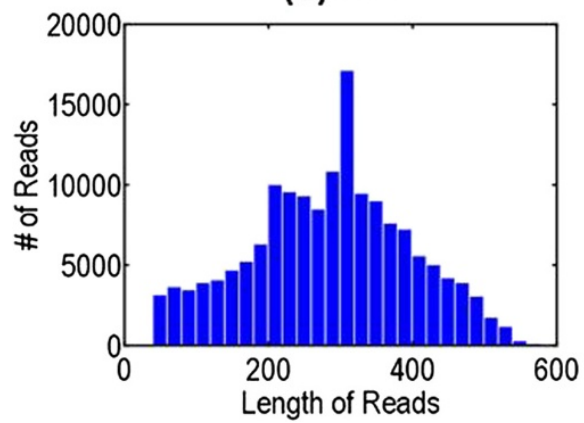

(D) AdS

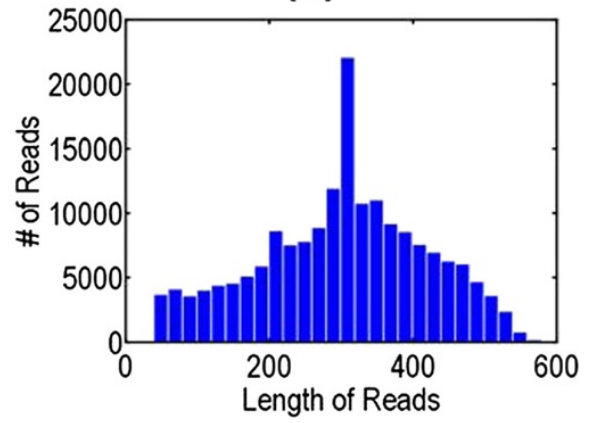

Figure 1454 GS FLEX Titanium read length distribution for each library (bp). Asl- A. stenosperma inoculated with C. personatum; AsC- A. stenosperma control; AdS- A. duranensis under water limited stress; AdC-A.duranensis control. 
Table 2 Total number of unigenes and genome coverage for each species

\begin{tabular}{lllll}
\hline & A. stenosperma & A. duranensis & Average number for both species & Total number in both species \\
\hline Number of high quality reads & 310,430 & 276,884 & 293,657 & 587,314 \\
Number of reads after clustering & 253,134 & 238,456 & 245,795 & 491,590 \\
*Percentage of accepted reads (\%) & 81.54 & 86.12 & 83.83 & - \\
Number of unigenes & 17,912 & 21,714 & 19,813 & 39,626 \\
Number of contigs & 7,723 & 12,792 & 10,257 & - \\
Average contigs length (bp) & 457 & 494 & 475.5 & - \\
Average number of reads per contig & 33 & 19 & 26 & 18.91 \\
Contig genome coverage (Mbp) & 8.18 & 10.72 & 9.45 & - \\
\hline
\end{tabular}

*The index is calculated as the percentage of the total number of high-quality sequence reads per number of reads after clustering.

\section{Sequence annotation and gene ontology}

Only the high confidence consensus sequences (contigs) of A. stenosperma and A. duranensis were compared against the NCBI non-redundant protein sequence database (nr) for each species using BLASTX [36] in order to annotate known proteins/genes (Additional files 1, 2). A relatively high rate of contigs, $52.3 \%$ from $A$. stenosperma and $58.5 \%$ from $A$. duranensis, could be assigned to putative orthologs of genes involved in various pathways and cellular processes, when compared to other legumes without a completely annotated reference genome sequence $[27,29]$. Over $27 \%$ of the overall transcripts in both, $A$. stenosperma and $A$. duranensis showed homology in BLASTX to 14 legume species (Additional files 1 and 2). From these, over $60 \%$ of $A$. stenosperma and $A$. duranensis transcripts showed homology to Glycine max, followed by Medicago spp. (18\%). Only $2.9 \%$ of $A$. stenosperma transcripts showed homology to A. hypogaea, whilst $6.5 \%$ showed homology to $A$. duranensis. This data reflects the greater number of ESTs available for these two legumes in comparison with Arachis spp. and also the closeness of $A$. duranensis to the cultivated tetraploid A. hypogaea [37].

For functional annotation, Blast2GO [38] was applied to classify contigs at superfamily, family and subfamily levels, to predict the occurrence of functional domains, repeats and important sites, and to include GO (Gene Ontology) terms to the protein signatures. From the 7,723 contigs in A. stenosperma, 96\% (7,391) could be assigned to one or more GO annotation category, with 2,925 (39\%) attributed to a biological process, 2,144 (29\%) to a cellular component and 3,338 to a molecular function (45\%) (Figure 3). Likewise, in A. duranensis, an equally high amount (12,024 contigs; $94 \%)$ of the 12,792 contigs could be appointed to GO annotation categories, with 4,752 (39\%) identified as belonging to a biological process, $3,135(26 \%)$ to a cellular component and 5,937 (49\%) to a molecular function (Figure 3 ).

The assignments made to the molecular function ontology was very similar for both species (Figure 3), with a large proportion of the sequences in catalytic
(12-15\%) and binding activities (14-17\%), whilst under the biological process ontology a large proportion fell into metabolic process (15-17\%) and cellular process (13\%). Additionally, in A. stenosperma, including transcripts from fungi inoculated leaves, 68 sequences were identified in the GO subcategory response to stimulus which included peroxidases, catalases, chitinases, glycosinases and serine/threonine kinases, whilst in A. duranensis, including transcripts from leaves and roots submitted to water limited stress, 126 sequences were in this category with highlight to those sequences related to osmotic stress and water deprivation (Figure 3 ).

\section{Transcription factors}

Transcription factors (TFs) constituted up to $1 \%$ of the total high confidence consensus sequences in both species studied, and were classified in TF families by sequence comparison to known transcription factor gene families at a Plant TF public database [39] (Figure 4). In this study, all TF $A$. duranensis transcripts were classified in 25 families that play important roles in eliciting stress responses such as bZIP (13\%), MYB (13\%), NAC (7\%), bHLH and AP2-EREB (8\%) and WRK (6\%), the latter being the most highly represented (Figure 4A). In $A$. stenosperma, a slightly different distribution of the TFs in 20 families was observed with bZIp (18\%), MYB (14\%), AP2-EREB (10\%), bHLH (6\%) and WRK (4\%), also being the most represented (Figure 4B).

\section{Expression profile of RGAs and FIDEL}

The largest class of known plant disease resistance (R) proteins includes those that contain a nucleotide binding site and leucine-rich repeat domains (NBS-LRR proteins). NBS-LRR proteins may recognize the presence of a pathogen directly or indirectly [40]. A total of 48 homologs of Arabidopsis NBS encoding genes was identified in A. stenosperma according to previous methodology [41], of which five representatives were selected for further expression analysis (Additional file 3). Those five genes were analyzed by qRT-PCR, using cDNA from C. personatum inoculated plants and the respective 


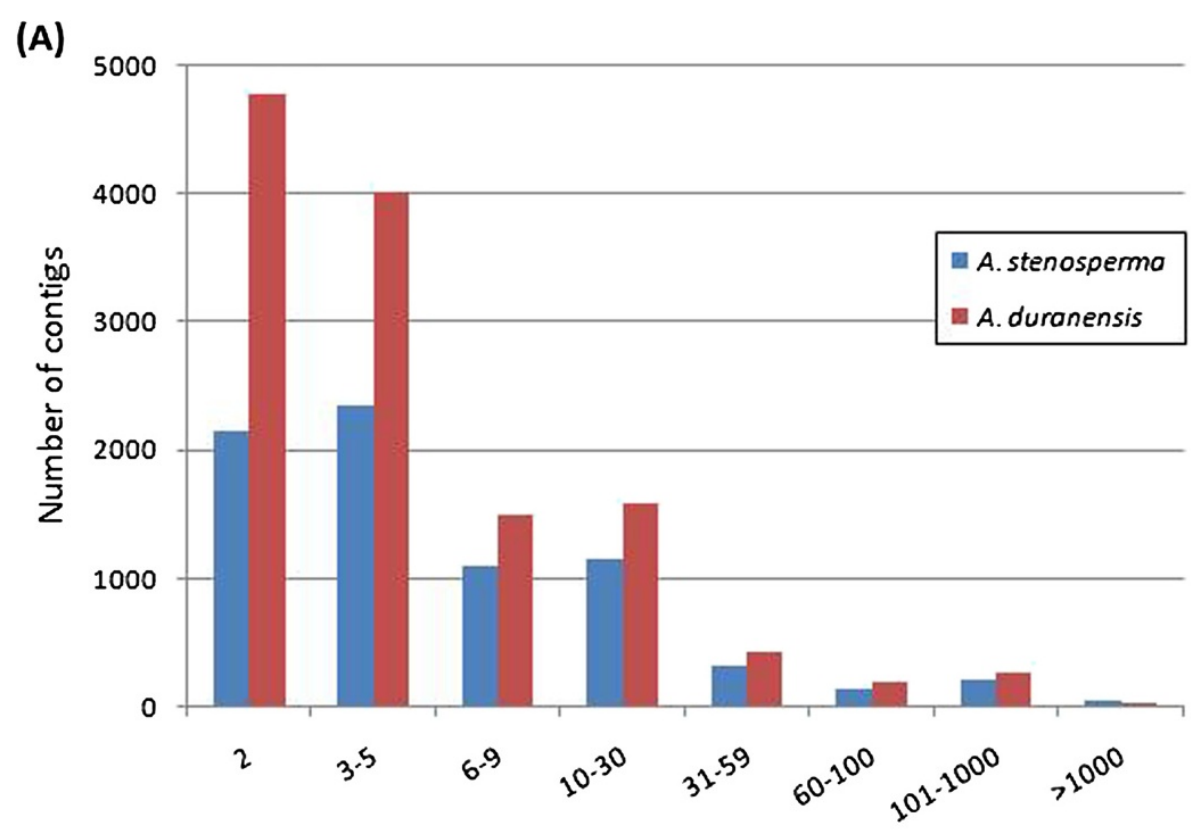

Number of reads

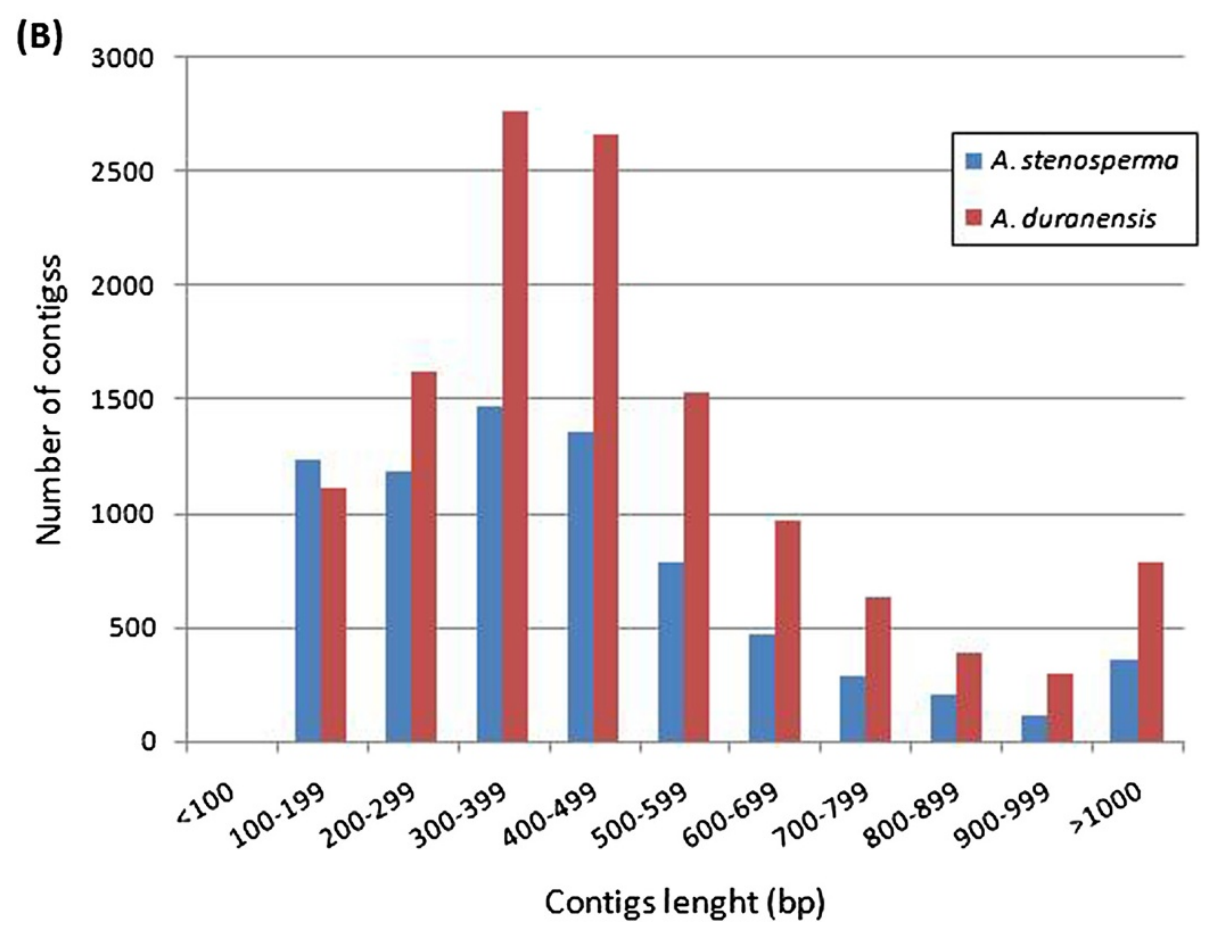

Figure 2 Distribution of contigs by number of reads (A) and length (B).

controls as template, RGA primers described in Table 3, and $60 \mathrm{~S}$ as the reference gene, according to [42]. Relative quantification of transcripts showed that all five RGAs were up regulated in fungi-challenged plants in comparison to the control, with RGAs 256, 122 and 11 showing the biggest differences in expression levels (Figure 5A).
Retroelements constitute the major part of repetitive DNA of a number of animal and plant genomes [43]. The long terminal repeat (LTR) retrotransposon-FIDEL constitutes a significant part of Arachis tetraploid and diploid genomes [20]. FIDEL-related sequences were found to be expressed in both species studied with a 


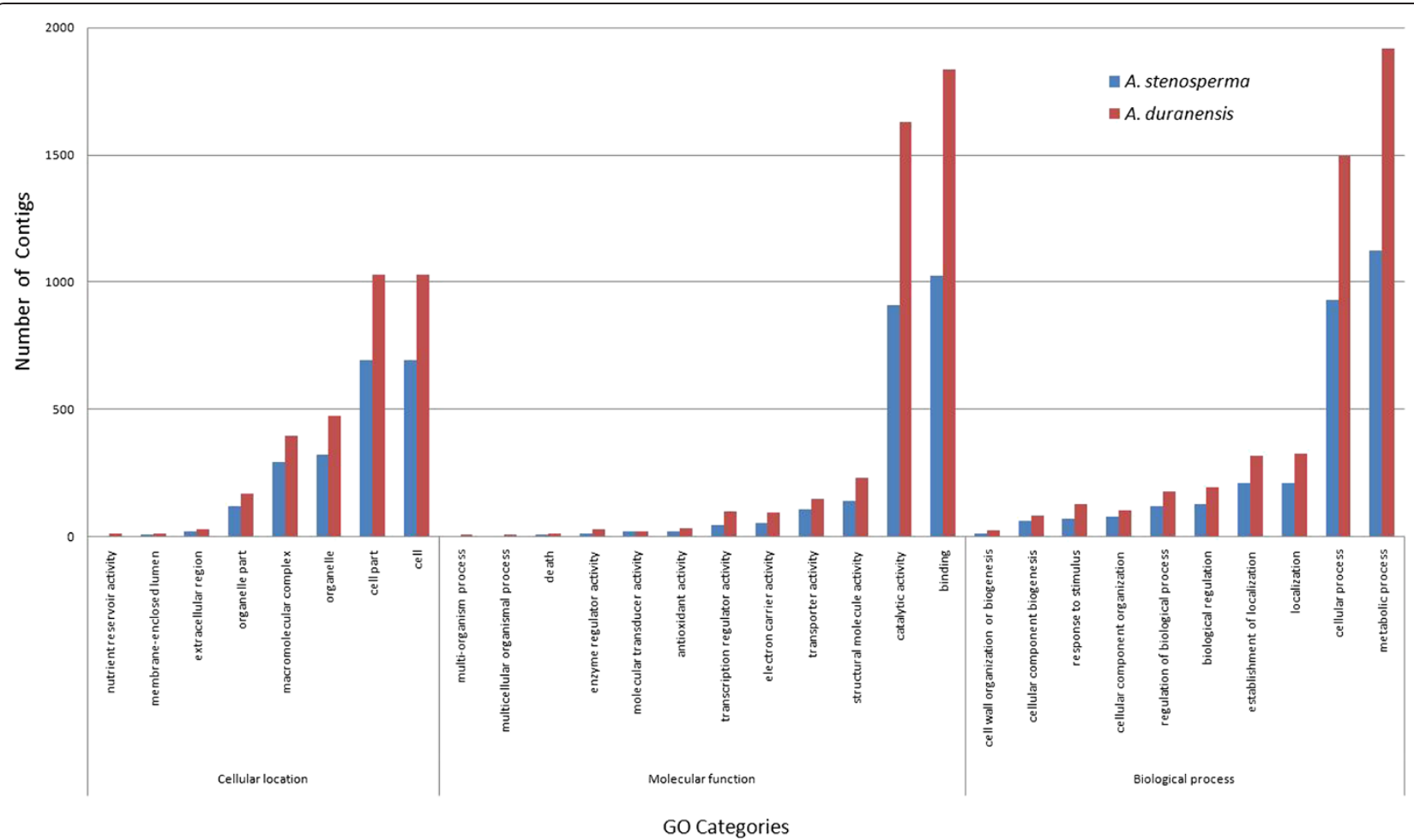

Figure $3 \mathrm{GO}$ Annotation analysis for contigs from A. stenosperma and A. duranensis. Gene Ontology (GO) classification of the predicted A. stenosperma (blue) and A. duranensis (red) ORFs according to cellular location, molecular function and biological process using Blast2GO with e-10 cutoff.

surprisingly high frequency. For A. duranensis, $0.23 \%$ of the high quality sequence reads, and 37 of the 12,792 $(0.29 \%)$ contigs were FIDEL or FIDEL-related. For A. stenosperma, $1.3 \%$ of the high quality sequence reads, and 87 of the $7,465(1.16 \%)$ contigs were FIDEL or FIDELrelated. In silico analysis indicated that most of these contigs were up regulated in response to the biotic/abiotic stresses. Four FIDEL-related contigs (Table 3) were chosen for analysis by qRT-PCR using cDNA from $A$. stenosperma leaves and A. duranensis roots, as template, and actin or $60 \mathrm{~S}$ as reference genes.

We found that, with the exception of FIDEL274 in $A$. stenosperma/C. personatum samples, all representatives of this retroelement showed an increased expression in both species under biotic and abiotic stress (Table 3; Figure 5B). It is also interesting to note that, the levels of induction of the four FIDEL sequences were slightly higher in $A$. duranensis submitted to water limited stress than in A. stenosperma under fungi inoculation (Figure 5). The sequence FIDEL 412 showed the highest difference in expression levels between stressed and non-stressed plants with 1.74-fold expression ratio (Figure 5B).

\section{SSR identification}

The discovery of EST-SSRs in the transcriptome of both species, $A$. duranensis and A. stenosperma, was performed based on the analysis from assembled contig templates. A total of 2,884 distinct SSR loci were identified, and 1,463 primer pairs were designed for A. duranensis and 862 for A. stenosperma corresponding to 11 and $10 \%$ of total contigs, respectively. Table 4 shows the information regarding the primer design and the frequency of different repeat types. Overall, the most abundant SSR type was trinucleotides $(57 \%)$ followed by tetra/penta $(20 \%)$ and dinucleotides (12\%). More details about the primers are provided in Additional file 4. Thirty-one EST-SSRs identified had been identified in a previous study [17] and were already mapped in the A-genome mapping population (A. stenosperma X A. duranensis) [11,19] (Additional file 4). The 2,324 primer pairs designed were submitted to ePCR [44] and 584 amplified in both species. Of these, 214 showed to be polymorphic for $A$. duranensis and $A$. stenosperma, which are the parents of a RIL mapping population. Some of these newly developed markers will be included in the saturated linkage map that is being constructed for the A-genome of Arachis using this RIL population.

\section{Discussion}

Transcriptome sequences are a valuable resource, especially for species without a completely sequenced genome, such as peanut. They accelerate gene discovery, 


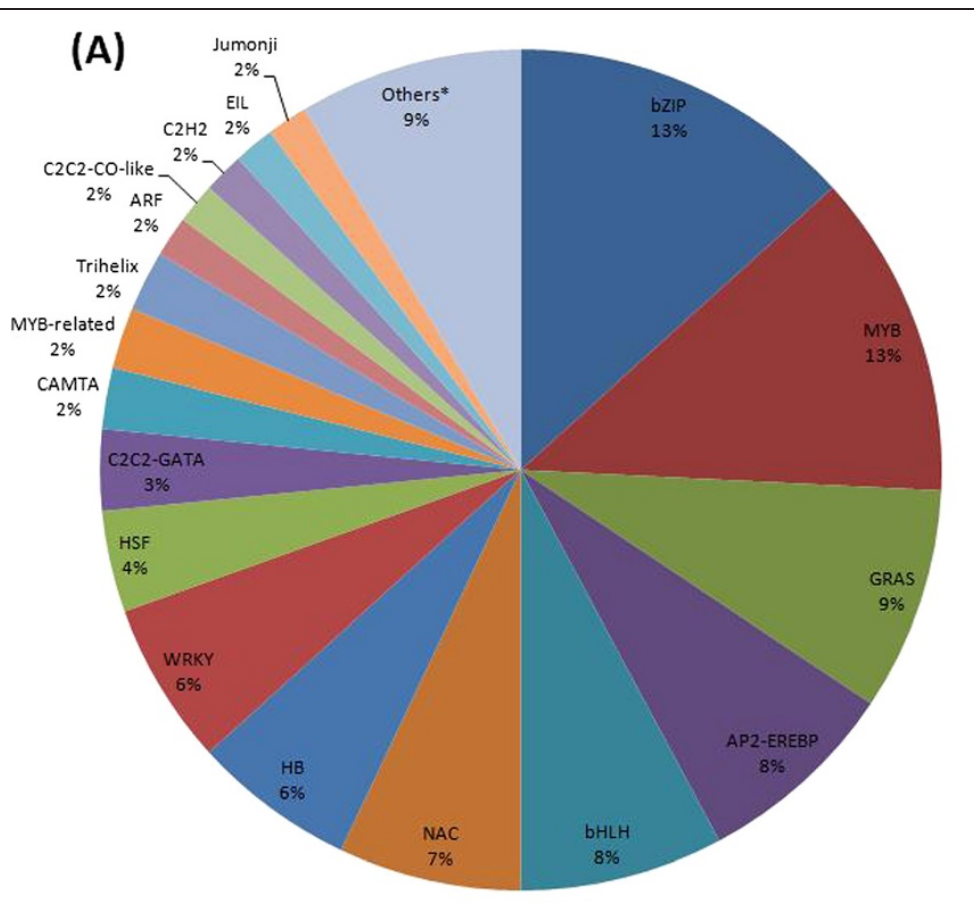

*Others ( $\leq 1 \%$ ): Alfin-like; BBR/BPC; CCAAT; G2-like; GeBP;IWS1; MADS; RWP-RK; TCP; TUB and zf-HD.

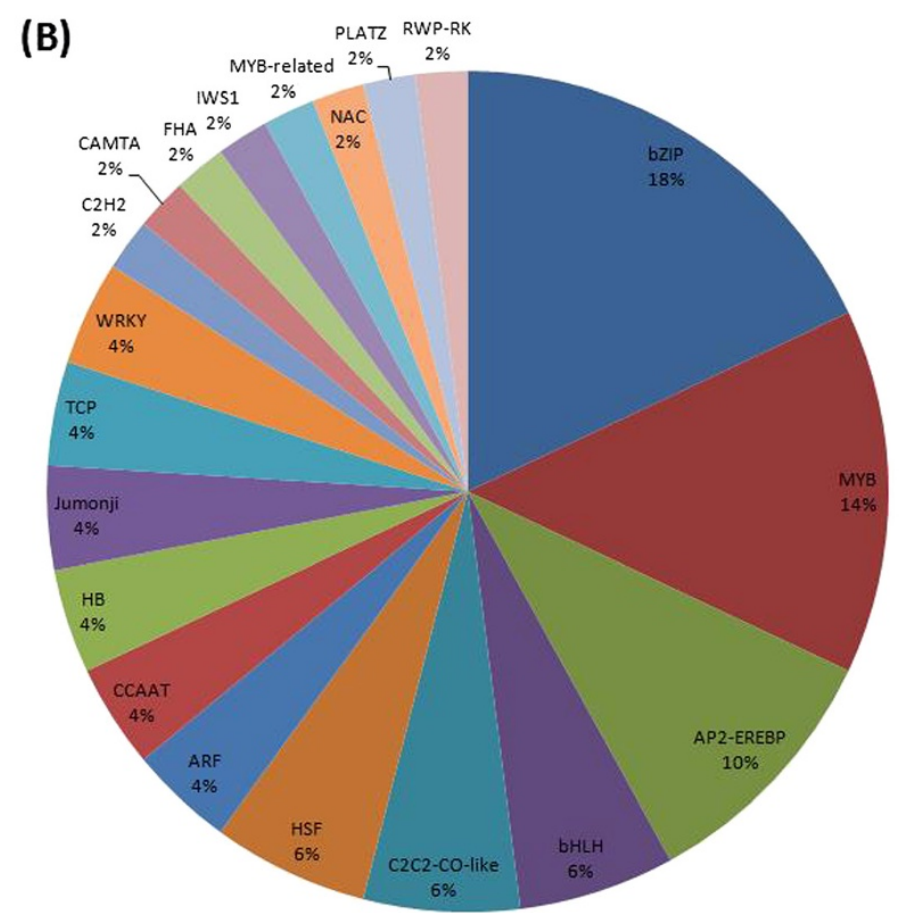

Figure 4 Distribution of contigs of $A$. Duranensis (A) and A. stenosperma (B) by transcription factor (TF) families. Transcription factors (TFs) identified by conserved domain annotation BLASTX with e-7 cutoff.

provide an asset for molecular markers development and allow expression analysis and evolutionary genome dynamics studies. In the present study, Next Generation Sequencing (NGS) enabled the generation of large numbers of sequence reads in a rapid and cost-effective manner, and enabled the development of genomic resources for the exploitation of the stress resistances harbored by two wild diploid relatives of peanut. 
Table 3 NBS-LRR and FIDEL sequences used for expression analysis using qRT-PCR

\begin{tabular}{|c|c|c|c|c|}
\hline Gene/Sequence abbreviation & Primer sequence Forward/Reverse & Amplicon size (bp) & PCR efficiency (\%) & Regression coefficient $\mathrm{R}^{2}$ \\
\hline \multirow[t]{2}{*}{ RGA11 } & GGCAAAGGTGATGCTACCTG/ & 160 & 95.86 & 0.996 \\
\hline & TTCCCAAGGAAGTTGATCCT & & & \\
\hline \multirow[t]{2}{*}{ RGA122 } & TTGCACCAACTTCTGGTTTG/ & 156 & 94.41 & 0.979 \\
\hline & CAATGATATGCCCCGTCTCT & & & \\
\hline \multirow[t]{2}{*}{ RGA156 } & TCTAGAAAGCGAGGAGCTCAA/ & 157 & 96.09 & 0.991 \\
\hline & TGGATTGACTGGGATATGCTC & & & \\
\hline \multirow[t]{2}{*}{ RGA256 } & AGCTTCACGGTGAGGAAGAA & 178 & 93.09 & 0.981 \\
\hline & ATTCCGTGTTGCAGAACCTC & & & \\
\hline \multirow[t]{2}{*}{ RGA390 } & CAGAACAACGAGAACAATCG/ & 150 & 104.76 & 0.999 \\
\hline & TTACCGTCATCCGAAACTTG & & & \\
\hline \multirow[t]{2}{*}{ FIDEL197 } & TGGCTACATCCCATCCTCTC/ & 167 & 113.25 & 0.994 \\
\hline & GGGATTGAATGACTGTGACG & & & \\
\hline \multirow[t]{2}{*}{ FIDEL274 } & AGCTTITTGCTTCGGAACAG/ & 161 & 95.92 & 0.903 \\
\hline & GGGTCACAGCCAAGACTCAT & & & \\
\hline \multirow[t]{2}{*}{ FIDEL412 } & GAGTTAAACGCCAGCTTTGG/ & 183 & 95.25 & 0.999 \\
\hline & CGGCGTTGGAAAGTAGACAT & & & \\
\hline \multirow[t]{2}{*}{ FIDEL496 } & GCAAGCTCGTGTAGGGTTTC/ & 157 & 110.58 & 0.997 \\
\hline & GCGTTAGTGACAGACGCAAA & & & \\
\hline \multirow[t]{2}{*}{$60 S^{*}$} & TGGAGTGAGAGGTGCATTTG/ & 155 & 102.36 & 0.998 \\
\hline & TCTITGACGACCAGGGAAC & & & \\
\hline \multirow[t]{2}{*}{$\mathrm{ACT} 1^{*}$} & TGGTCTCGGTTTCCTGAGTT/ & 114 & 94.13 & 0.995 \\
\hline & AATACCACTCCAAAGCAAACG & & & \\
\hline
\end{tabular}

Some recent studies have indicated that short reads from 454 GS 20 and GS FLX can effectively be used to characterize gene regions in a number of less studied species, including some tropical legumes [26,28$30,45,46]$. In the present study, the average read length for both species was of $280 \mathrm{bp}$, which allowed estimated genome coverage of up to $163 \mathrm{Mbp}$ of high quality reads for both diploid Arachis genomes studied in a single sequencing run. In comparison with other studies in legumes, a relatively small number of singletons were produced (8,922 for A. duranensis and 10,189 for A. stenosperma), furthermore the average length and number of reads per contig assembled was comparatively high (475.5 bp and 26 reads/contig) (Table 2) [27,29,47]. This may in part be due to very stringent quality and assembly parameters used, which also may partly explain that only $5 \%$ of the contigs produced in this study $(1,012)$ failed to show significant functional annotation.

The lack of a complete sequenced and annotated reference genome makes it very difficult to estimate the genome coverage obtained in this study for both species analyzed. However, if we take as comparison other diploid legume genomes which have already been completely sequenced and assume the same number of genes, as for Medicago truncatula $(38,835)$ and Lotus japonicus $(42,395)$, we could suggest that up to $54 \%$ of the $A$. duranensis $(21,714)$ and $44 \%$ of $A$. stenosperma $(17,912)$ unigenes were covered in our work. However, it is also important to be aware that more than one contig or singleton can be originated from a single gene due to either non-overlapping sequence reads or high levels of sequence error in a single read [27].

Transcription factors (TFs) are of special interest due to their role in controlling plant developmental processes and responses to environmental conditions, including functions of key importance to agronomic performance [24]. They have an essential role in the signal transduction networks that leads from the perception of stress signals to the expression of stressresponsive genes, and, as opposed to most structural genes, tend to control multiple pathway steps within a transcriptional cascade [25]. Therefore, TFs are expected to be excellent candidates for modifying complex traits in crop plants, with TF-based technologies likely to be a prominent part of the next generation of successful biotechnology crops $[48,49]$. In the present study, $1 \%$ of the 


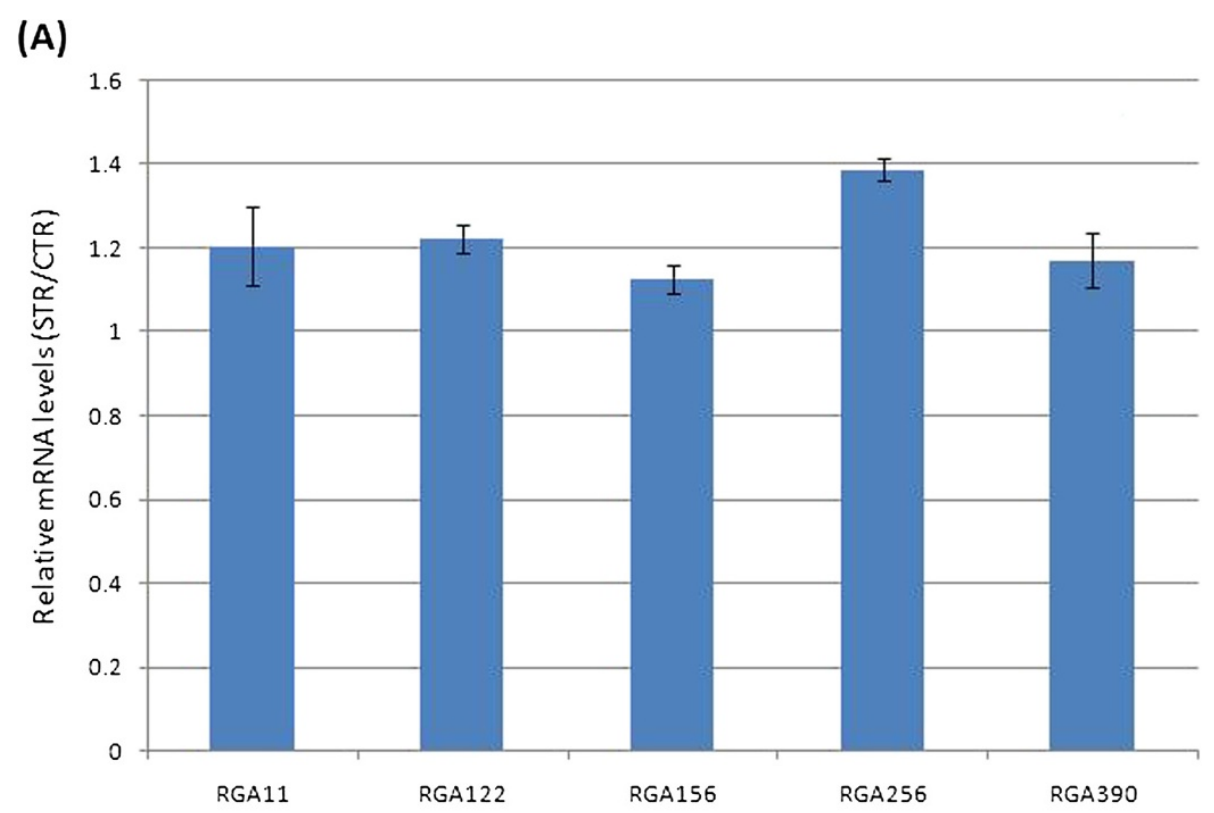

(B)

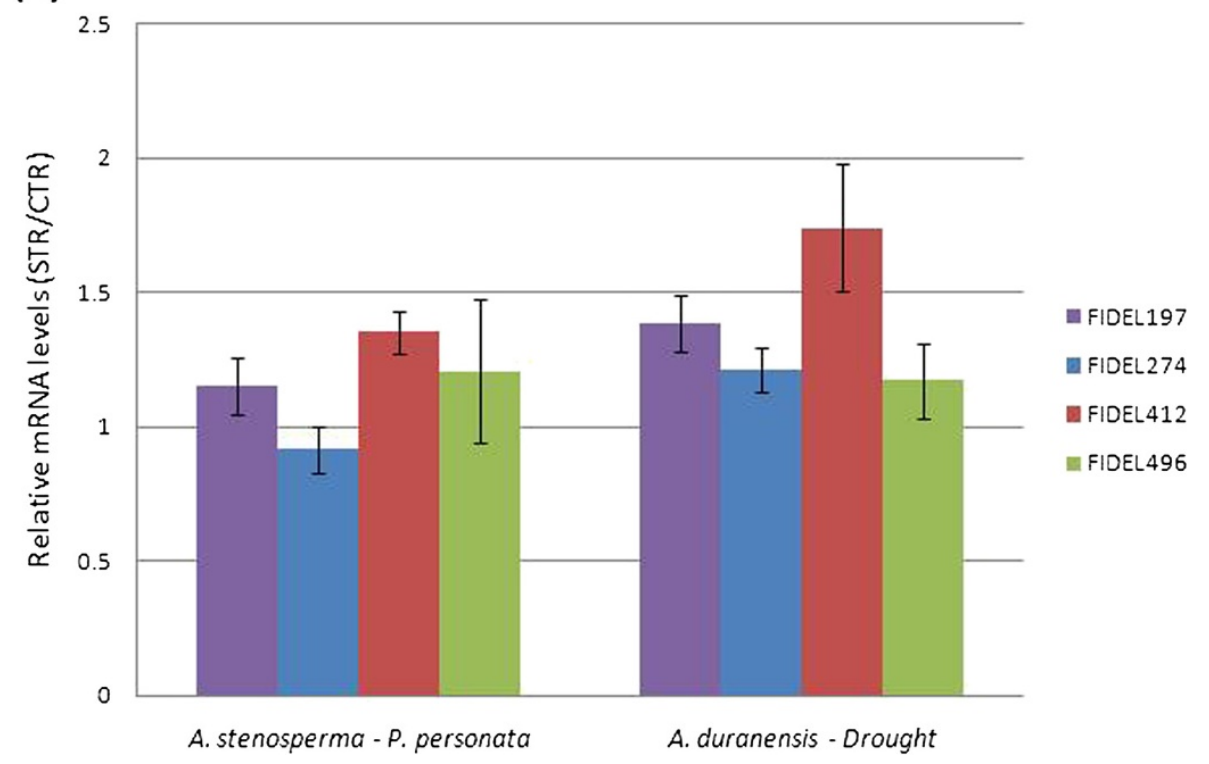

Figure 5 Relative mRNA levels produced by five NBS-LRR sequences in A. stenosperma leaves inoculated with C. personatum (A) and by four FIDEL sequences in water limited stressed $A$. duranensis roots (B). Normalization of expression was performed using as references the 605 gene for A. stenosperma and the actin gene for A. duranensis samples. Bars represent the standard error of the mean of two biological replicates for each sample.

transcripts were identified as transcription factors (TFs). Their overall distribution among the various known TF protein families was compatible with previous studies in other legumes such as soybean, chickpea, pigeonpea and cultivated peanut $[4,28,30,50,51]$, with bZIP, MYB, NAC, bHLH, AP2-EREBP and WRKY highly represented in both A. duranensis and A. stenosperma transcripts.

The most expressed TF family was the basic leucine zipper (bZIP)-type TF protein, which comprise regulators of many central developmental and physiological processes and abiotic and biotic stress responses [52]. Among other reports, this TF has been associated with water deficit-response in the relatively drought resistant tepary bean (Phaseolus acutifolius) [53] and to abscisic acid (ABA)-regulated gene expression required for the dehydration-response in Arabidopsis [54]. Likewise, this TF family was the most expressed in A. duranensis plants subjected to gradual water limited stress (18\%), 
Table 4 Frequency and repeat type of SSRs in $A$.

\begin{tabular}{|c|c|c|c|}
\hline SSR mining & A. duranensis & A. stenosperma & Total \\
\hline Total sequences analyzed & 13,132 & 8,480 & 21,612 \\
\hline Total sequences with repeats & 1,701 & 1,183 & 2,884 \\
\hline Total primers designed & 1,463 & 862 & 2,324 \\
\hline \multicolumn{4}{|l|}{ SSR in repeat types } \\
\hline Di-nucleotide & 157 & 115 & 272 \\
\hline Tri-nucleotide & 838 & 488 & 1,326 \\
\hline Tetra,Penta-nucleotide & 315 & 161 & 476 \\
\hline Hexa-nucleotide & 153 & 98 & 251 \\
\hline \multicolumn{4}{|l|}{ SSR polymorphism } \\
\hline Amplified in other parent* & 376 & 208 & 584 \\
\hline Polymorphic ${ }^{\S}$ & 142 & 72 & 214 \\
\hline $\begin{array}{l}\text { Percentage of polymorphic } \\
\text { primers }\end{array}$ & - & - & 36.6 \\
\hline
\end{tabular}

* SSRs identified in one parent also amplified in the other parent.

$\S$ Polymorphic SSRs identified from the set of primers amplifying in both species.

suggesting a role of this family in this relatively drought tolerant species. The bZIP TF family was also the most expressed TF in A. stenosperma leaves subjected to $C$. personatum (18\%), and has already been described as involved in defense response to other host-fungi interactions, such as to the stripe rust via the ethylene/methyl jasmonate -dependent signal transduction pathways in wheat [55], and to regulate the expression of some stress-responsive genes such as the PR-1 and Glutathione S-Transferase in Arabidopsis [56].

The second most highly expressed TF family in drought imposed $A$. duranensis plants (12\%) and fungi infected $A$. stenosperma leaves (14\%) was the MYB family, which has been described to act through the ABA signaling cascade to regulate stomatal movement and therefore water loss regulation, and disease resistance in Arabidopsis and rice $[57,58]$. Likewise, the plant specific NAC transcription family was showed to be highly expressed in $A$. duranensis (10\%) and to a lesser extent in $A$. stenosperma (2\%). NAC proteins function has been previously described in potato and Brassica napus under fungal infection $[59,60]$ and to significantly increase drought tolerance in soybean and chickpea [61,62].

Dehydration-responsive element binding (DREB) proteins a subgroup of the AP2/EREBP, have an important role in plant response and adaptation to abiotic stresses [63]. In this study, they constituted $7 \%$ of the TFs in $A$. duranensis plants subjected to water limited stress. A previous study with transgenic peanut plants over expressing DREB1A showed that the changes in the antioxidative machinery in these transgenic plants under water-limiting conditions played no causative role in improved transpiration efficiency $[5,64,65]$. Nonetheless, different DREB homologues have shown to play different roles in increasing tolerance to cold, salt and drought in different plant species, and have been extensively studied in Arabidopsis, rice and soybean being correlated to increased dehydration tolerance in these species [66-69]. An additional consideration is that recent studies indicate that function of central regulators as NAC, WRKY, and zinc finger proteins may be modulated by mechanisms such as small RNA (miRNA)-mediated posttranscriptional silencing, reactive oxygen species signaling and epigenetic processes such as DNA methylation and posttranslational modifications of histones [70]. This suggests that a more comprehensive elucidation of the role and dynamics of drought and defense responsive TFs in plants may be required.

Retroelements, particularly the long terminal repeat (LTR) retrotransposons, constitute the major part of repetitive DNA of plant genomes. Some of these elements seem to be constitutively expressed and others are silent and can be activated upon certain stress signals such as tissue culture, ionizing irradiation, wounding or poliploidization. As a matter of fact, data from the whole genome sequencing of several eukaryotes strongly suggests that, far from being circumstantial, the activity of transposable elements plays an extremely important role in the plasticity and regulation of host gene functions [71]. The mechanisms of how stress induces the activity of an element are not completely clarified, but it has been shown that most expression features of Tnt1, a Solanaceae retrotransposon, can be deduced from the structure of its regulatory regions, located in the LTR that contains several cis-acting elements, which are similar to well characterized motifs involved in activation of defense genes, whilst the Tnt1A G-box-like sequence is related to the typical ABA-responsive (ABRE) sequences and is identical to the $\mathrm{MYC}$ recognition sequence present in many drought-inducible genes [71,72].

In the present study, many transcripts from both species were identified as having similarity to retroelements. Therefore, we studied in more detail FIDEL, the only fully characterized Ty3-gypsy retrotransposon described in allotetraploid peanut (A. hypogaea) and its putative diploid ancestors $A$. duranensis (A genome) and $A$. ipaënsis (B genome) [20]. Using qRT-PCR analysis, we observed that FIDEL showed an increased expression ratio in both, $A$. duranensis roots subjected to gradual water limited stress and A. stenosperma leaves inoculated with fungus, when compared to non-challenged plants. In tobacco and other Solanaceae, drought stress and fungi infection have been described as triggering independent mechanisms of plant defense response and activation of transcription factors and retroelements $[71,73]$. In our study, we observed that both biotic and abiotic stresses induced FIDEL or FIDEL-related 
sequences. However, if the induction of FIDEL represents an activation of some specific FIDEL sequences, FIDEL harboring regions or some more specific response is not known.

Plants, in response to pathogen effectors, have coevolved specific cytoplasm resistance $\mathrm{R}$ protein receptors which recognize individual pathogen effector molecular signatures and activate a second line of defense known as effector-triggered immunity (ETI) [74], also previously known as gene-for-gene or race-specific resistance. In contrast to non-specific response (PAMP-triggered immunity-PTI), which will occur in all members of a particular plant species, ETI operates at the intra-specific level, with resistant genotypes possessing the necessary $\mathrm{R}$ gene allele [75]. Conservation of motifs within $\mathrm{R}$ genes, such as those present within nucleotide-binding site leucine rich repeat domains, have facilitated their characterization in diverse plant taxa. Putative $\mathrm{R}$ genes or Resistance Gene Analogs (RGAs) are commonly clustered, as a result of duplication events occurring under diversifying selection. In Arachis, a previous investigation on RGAs content in a number of wild species [41] showed that from the $78 \mathrm{NBS}$ sequences identified, most fall within legume-specific clades, some of which appear to have undergone extensive copy number expansions. In the present study, all five RGA sequences showed an increase on expression under C. personatum inoculation, when compared to the basal expression in the control samples. This was hardly unexpected, as proteins encoded by disease resistance ( $R$ ) genes, are mostly constitutively expressed in resistant genotypes, mediating specific molecular recognition of pathogenic microorganisms and triggering signaling cascades that activate defense reactions [76,77]. A broader characterization of the transcriptional response of a suite of defense genes following stimulation of these R-genes, (i.e. kinases, peroxidases, transcription factors, NPR1) [78], and the defense pathways that they trigger is being conducted via Illumina deep sequencing. This will allow a better understanding of their contribution to the overall resistance response of $A$. stenosperma to $C$. personatum.

The transcriptome databank produced in this study enabled the development of 2325 SSR primer pairs of which 214 showed to be polymorphic between the two species. These new markers will enrich the current reference AA diploid Arachis map [19] and other Arachis tetraploid maps under construction. In addition, these EST-SSRs markers exhibit potential advantages when compared to SSRs located in non-transcribed regions due to generally more consistent efficiency of amplification, and enhanced cross-species transferability [27].

The development of new SSRs is of special interest in Arachis because these are still the markers of choice in this genus, due to the difficulties in the application of
SNPs markers on the cultivated tetraploid species. Therefore, these new markers will contribute to enrich existing genetic maps, generate more informative genetic and genomic tools and enable the identification of orthologous genes through genome synteny analysis [15].

\section{Conclusions}

The use of NGS for transcriptome sequencing of species without a complete reference genome is an effective approach for gene discovery and identification of transcripts involved in specific biological processes. The present work constitutes the largest unigene dataset for A. stenosperma and the second for A. duranensis, providing an insight into genomic architecture of these species and also creating a scaffold of transcribed sequences which will help to elucidate genes involved in biological processes such as fungi and drought- related response genes.

\section{Methods}

\section{Plant material and library construction}

Seeds of A. stenosperma (V10309) and A. duranensis (K7988) were obtained from the Brazilian Arachis Germplasm Collection, and maintained at Embrapa Genetic Resources and Biotechnology (Brasilia-DF, Brazil). For fungi bioassays, two month old plants of A. stenosperma were inoculated with a 50,000 spores $/ \mathrm{ml}$ suspension in $0.5 \%$ Tween 20. Plant leaves were collected at 24, 48 and 72 hours after inoculation (HAI) and from noninoculated controls, as described in our previous work [42], and immediately frozen on liquid nitrogen for RNA extraction.

For gradual water limited stress experiments, A. duranensis three months-old plants were equally divided into two groups of 33 individuals each: one group was subjected to a gradual water limited stress (STR), whilst the control group (CTR) was kept at approximately $70 \%$ of field capacity. Daily individual transpiration rate of STR and CTR plants was estimated gravimetrically and no more than $10 \mathrm{~g}$ of water loss per day was allowed in STR plants. Normalized Transpiration Ratio (NTR) was calculated between individual transpiration of STR and the mean transpiration of CTR plants, essentially as described by [79]. Leaves and roots were collected at distinct stages of the progressive water deficit (decreasing NTRs: $0.76 ; 0.73 ; 0.57 ; 0.43$ and 0.40 ) and immediately frozen on liquid nitrogen to proceed RNA extraction.

Total RNA was extracted from $250 \mathrm{mg}$ of plant material as previously described [42]. RNA integrity was checked by gel electrophoresis and quantified using Nanodrop ND-1000 (Thermo Scientific, Waltham, USA). To construct four bulked libraries, equal amounts of total RNA for inoculated A. stenosperma (leaves 
collected at 24, 48 and $72 \mathrm{HAI}$ ) and stressed A. duranensis (leaves and roots from all NTR points) were pooled separately from their respective non-treated controls and used for mRNA isolation. For the cDNA libraries construction and sequencing, services of $\mathrm{CD}$-Genomics (www.cd-genomics.com) were used employing the Creator SMART cDNA library construction kit (Clontech Laboratories, California, USA) and Roche 454 GS-FLX System with Titanium chemistry.

\section{Sequence processing and assembly}

Raw 454 data was pre-processed using est2assembly [80] for contaminant removal (non-coding RNA and plastidial sequences), quality trimming and adaptor trimming and poly-A removal. Transcript clustering was carried out using MIRA [81].

\section{Similarity search and functional annotation}

Functional annotation of the cluster consensi was performed by sequence similarity searches using BLASTX program [36] against NCBI's non-redundant sequence database. InterProScan [38] was employed to perform protein domain and motif searches. Gene ontology (GO) terms were assigned by Blast2GO [82].

For the identification of NBS encoding genes in A. stenosperma, predicted Arabidopsis NBS containing proteins identified as described in [41] were used as a BLAST database against which, all A. stenosperma contigs were used as query sequences in a BLASTX search. BLAST detected similarities were considered significant with E-values of 1e-7 or less (Additional file 3). Similarly, predicted FIDEL sequences identified in previous studies [20] were used as a BLAST database against which all $A$. stenosperma and $A$. duranensis contigs were used as query sequences in a BLASTX search (E value $<1 \mathrm{e}-7)$.

For the identification of TF families represented in this study, from the functional BLASTX annotation (value < 1e-7), all putative TF genes from both Arachis species were selected and, classified according to their respective TF family using the Plant TF database [39].

\section{SSRs identification}

The program Mreps [83] was employed for the identification of simple sequence repeat (SSR) along the sequences. The parameters were set to identify perfect di- to hexa-nucleotide repeats with a minimum length of 12 bases. A series of custom-made PERL scripts were created to processes the potential SSR loci and to create flanking primers, based on Primer3 [84]. Electronic PCR was carried out using the PrimerMatch package [85] for the identification of primers amplifying in both species, and from these, the polymorphic set between $A$. duranensis and A. stenosperma.

\section{Expression analysis by qRT-PCR}

Plant materials were obtained in new independent experiments carried out as described above.

After isolation and purification, total RNA of four samples (A.stenosperma leaves inoculated with C. personatum and $A$. duranensis roots stressed by water limitation and their respective non-treated controls) was digested with DNase (TURBO DNA-free ${ }^{\mathrm{Tm}}$, Ambion, USA) and reverse-transcribed using SuperScript ${ }^{\mathrm{m}}$ II RT and Anchored Oligo(dT)20 primer (Invitrogen, Carlsbad, CA, USA), as previously described [42]. For qRT-PCR, the Platinum ${ }^{\circledR}$ SYBR $^{\circledR}$ Green qPCR Super Mix-UDG w/ ROX kit (Invitrogen, Carlsbad, CA, USA) was used according to manufacturer's recommendations on a $\mathrm{ABI}$ 7300 Real-Time PCR System (Applied Biosystem Foster City, CA, USA). Two biological replicates for each of four samples were used for real-time PCR analysis, with each replicate representing a pool of five plants. Reactions were carried out using three technical replicates for each sample. Specific primer pairs were designed for five RGAs and four Fidel - related sequences (Table 3) with Primer3Plus software [84] and qRT-PCR cycling conditions were carried out with a final dissociation curve step, using previously described parameters [42]. Normalization of expression was performed using as references the $60 \mathrm{~S}$ gene for A. stenosperma and the actin gene for A. duranensis samples [42]. All calculations for relative quantification, such as amplification efficiencies, correlation coefficients R2 values and relative expression profile (comparative $C t$ method) were performed using 7500 v.2.0.4 software (Applied Biosystem, Foster City, CA, USA).

\section{Additional files}

Additional file 1: Consensus sequences of assembled contigs of $A$. stenosperma and bioinformatic annotation (BLASTX). The data

represents the consensus sequences of 7,468 assembled contigs of $A$. stenosperma generated as a result of de novo assembly and the three best BLASTX scoring hits obtained as a result of comparison of $A$. stenosperma contig set against $\mathrm{nr}$ database of GenBank at an E value $<\mathrm{e}-7$.

Additional file 2: Consensus sequences of assembled contigs of $A$. duranensis and bioinformatic annotation (BLASTX). The data represents the consensus sequences of 12,791 assembled contigs of $A$. duranensis generated as a result of de novo assembly and the three best BLAST X scoring hits obtained as a result of comparison of $A$. duranensis contig set against nr databse of GenBank at an E value $<$ e-7.

Additional file 3: Bioinformatic annotation (BLASTX) of $A$. stenosperma contig set against Arabidopsis thaliana genome. This file contains the BLAST $X$ results obtained as a result of comparison of $A$. stenosperma contig set against $A$. thaliana predicted NBS containing proteins.

Additional file 4: Sequence information of all SSR primer pairs designed using MREPS. A stenosperma and A. duranensis primer pairs identified and designed using MREPS and other information (sequence information, orientation, sequence length, expected product length, Tm and SSR motif length). 


\section{Competing interests}

The authors declare that they have no competing interests.

\section{Authors' contributions}

PMG conceived the study, produced the RNA samples and drafted the manuscript. ACMB produced the RNA samples, the qRT-PCR data and contributed to the writing of the manuscript. CM produced the RNA samples and the qRT-PCR data. AM produced the RNA samples and the qRT-PCR data. GP performed the bioinformatics analysis. OBSJr performed the bioinformatics analysis. RT performed the bioinformatics analysis. SCMLB performed the drought and fungi bioassays and contributed to the writing of the manuscript. ACGA performed the drought and fungi bioassays and contributed to the writing of the manuscript. MCM performed the SSR analysis. DJB conceived the study, performed the SSR analysis and contributed to the writing of the manuscript. All authors read and approved the final manuscript.

\section{Acknowledgements}

This work was funded by the host institutions and Fundação de Apoio à Pesquisa do Distrito Federal (FAP/DF) and The National Council for Scientific and Technological Development (CNPq), Brazil.

\section{Author details}

${ }^{1}$ EMBRAPA Recursos Genéticos e Biotecnologia. Parque Estação Biológica, CP 02372 Final W5 Norte, Brasília, DF, Brazil. EMBRAPA Semi -Árido, BR 428, Km 152, Zona Rural - CP 23, Petrolina, PE, Brazil. ${ }^{3}$ Universidade de Brasília, Campus I, Brasília, DF, Brazil. ^Universidade Católica de Brasília, Campus II, 916 Norte, Brasília, DF, Brazil.

Received: 16 December 2011 Accepted: 5 June 2012

Published: 13 August 2012

\section{References}

1. The FAO Statistical Database (FAOSTAT): http://faostat.fao.org/site/567/ default.aspx.

2. Tillman BL, Stalker HT, Vollmann J, Rajcan I: Peanut-oil crops. In Handbook of Plant Breeding. Volume 4. Edited by Prohens J, Nuez F, Carena MJ. New York: Springer; 2010:287-315.

3. Payton P, Kottapalli KR, Rowland D, Faircloth W, Guo BZ, Burow M, Puppala N, Gallo M: Gene expression profiling in peanut using high density oligonucleotide microarrays. BMC Genomics 2009, 10:265.

4. Kumar K, Kirti P: Differential gene expression in Arachis diogoi upon interaction with peanut late leaf spot pathogen, Phaeoisariopsis personata and characterization of a pathogen induced cyclophilin. Plant Mol Biol 2011, 75:497-513.

5. Bhatnagar-Mathur P, Devi MJ, Reddy DS, Lavanya M, Vadez V, Serraj R, Yamaguchi-Shinozaki K, Sharma KK: Stress-inducible expression of At DREB1A in transgenic peanut (Arachis hypogaea L.) increases transpiration efficiency under water-limiting conditions. Plant Cell Rep 2007, 26:2071-2082.

6. Nelson SC, Simpson CE, Starr JL: Resistance to Meloidogyne arenaria in Arachis spp. germoplasm. Suppl J NEMATOL 1989, 21:654-660.

7. Freitas FO, Moretzsohn MC, Valls JFM: Genetic variability of Brazilian Indian landraces of Arachis hypogaea L. Genet Mol Res 2007, 6:675-684.

8. Bechara MD, Moretzsohn MC, Palmieri DA, Monteiro JP, Bacci M, Martins J, Valls JF, Lopes CR, Gimenes MA: Phylogenetic relationships in genus Arachis based on ITS and 5.8S rDNA sequences. BMC Plant Biol 2010 10:255-255.

9. Guimarães P, Brasileiro A, Proite K, de Araújo A, Leal-Bertioli S, Pic-Taylor A, da Silva F, Morgante C, Ribeiro S, Bertioli D: A study of gene expression in the nematode resistant wild peanut relative, Arachis stenosperma, in response to challenge with Meloidogyne arenaria. Trop Plant Biol 2010, 3:183-192.

10. Leal-Bertioli SCM, De Farias MP: Silva Pedro IT, Guimaraes PM, Brasileiro ACM, Bertioli DJ, De Araujo ACG: Ultrastructure of the initial interaction of Puccinia arachidis and Cercosporidium personatum with leaves of Arachis hypogaea and Arachis stenosperma. J Phytopathol 2010, 158:792796.

11. Leal-Bertioli SCM, Jose ACVF, Alves-Freitas DMT, Moretzsohn MC, Guimarães PM, Nielen S, Vidigal BS, Pereira RW, Pike J, Favero AP, et al: Identification of candidate genome regions controlling disease resistance in Arachis. BMC Plant Biol 2009, 9:112.

12. Kaprovicas G, Gregory WC: Taxonomia del gênero Arachis (Leguminosae) Bonplantia 1994, 8:1-186.

13. Valls JFM, Simpson CE: Taxonomy, natural distribution, and attributes of Arachis. In Biology and agronomy of forage Arachis. Edited by Kerridge PH B. Cali: CIAT; 1994:1-18.

14. Varshney R, Bertioli D, Moretzsohn M, Vadez V, Krishnamurthy L, Aruna R, Nigam S, Moss B, Seetha K, Ravi K, et al: The first SSR-based genetic linkage map for cultivated groundnut (Arachis hypogaea L.). TAG Theor Appl Genet 2009, 118:729-739.

15. Bertioli D, Moretzsohn M, Madsen LH, Sandal N, Leal-Bertioli S, Guimaraes P, Hougaard BK, Fredslund J, Schauser L, Nielsen AM, et al: An analysis of synteny of Arachis with Lotus and Medicago sheds new light on the structure, stability and evolution of legume genomes. BMC Genomics 2009, 10:45.

16. Guimarães PM, Garsmeur O, Proite K, Leal-Bertioli SC, Seijo G, Chaine C, Bertioli DJ, D'Hont A: BAC libraries construction from the ancestral diploid genomes of the allotetraploid cultivated peanut. BMC Plant Biol 2008, 8:14.

17. Proite K, Leal-Bertioli SC, Bertioli DJ, Moretzsohn MC, da Silva FR, Martins NF, Guimaraes PM: ESTs from a wild Arachis species for gene discovery and marker development. BMC Plant Biol 2007, 7:7.

18. Pandey MK, Monyo E, Ozias-Akins P, Liang X, Guimarães P, Nigam SN, Upadhyaya HD, Janila P, Zhang X, Guo B, et al: Advances in Arachis genomics for peanut improvement. Biotechnol Adv 2011, 30:639-651.

19. Moretzsohn MC, Leoi L, Proite K, Guimarães PM, Leal-Bertioli SCM, Gimenes MA, Martins WS, Valls JFM, Grattapaglia D, Bertioli DJ: A microsatellitebased, gene-rich linkage map for the AA genome of Arachis (Fabaceae). Theor Appl Genet 2005, 111:1060-1071.

20. Nielen S, Campos-Fonseca F, Leal-Bertioli S, Guimarães P, Seijo G, Town C, Arrial R, Bertioli D: FIDEL - a retrovirus-like retrotransposon and its distinct evolutionary histories in the A- and B-genome components of cultivated peanut. Chromosome Res 2010, 18:227-246.

21. Nielen S, Vidigal B, Leal-Bertioli S, Ratnaparkhe M, Paterson A, Garsmeur O, D'Hont A, Guimarães P, Bertioli D: Matita, a new retroelement from peanut: characterization and evolutionary context in the light of the Arachis A B genome divergence. Mol Genet Genomics 2011, 287:21-38.

22. Luo M, Dang P, Bausher MG, Holbrook CC, Lee RD, Lynch RE, Guo BZ: Identification of transcripts involved in resistance responses to leaf spot disease caused by Cercosporidium personatum in peanut (Arachis hypogaea). Phytopathology 2005, 95:381-387.

23. Ranganayakulu G, Chandraobulreddy $P$, Thippeswamy M, Veeranagamallaiah $G$, Sudhakar C: Identification of drought stress-responsive genes from drought-tolerant groundnut cultivar (Arachis hypogaea L. cv K-134) through analysis of subtracted expressed sequence tags. Acta Physiologiae Plantarum 2012, 34:361-377.

24. Libault M, Joshi T, Benedito VA, Xu D, Udvardi MK, Stacey G: Legume transcription factor genes: what makes legumes so special? Plant Physiol 2009, 151:991-1001.

25. Udvardi MK, Kakar K, Wandrey M, Montanari O, Murray J, Andriankaja A, Zhang J-Y, Benedito V, Hofer JMI, Chueng F, Town CD: Legume transcription factors: global regulators of plant development and response to the environment. Plant Physiol 2007, 144:538-549.

26. Parchman T, Geist K, Grahnen J, Benkman C, Buerkle CA: Transcriptome sequencing in an ecologically important tree species: assembly, annotation, and marker discovery. BMC Genomics 2010, 11:180.

27. Kaur S, Cogan N, Pembleton L, Shinozuka M, Savin K, Materne M, Forster J: Transcriptome sequencing of lentil based on second-generation technology permits large-scale unigene assembly and SSR marker discovery. BMC Genomics 2011, 12:265.

28. Hiremath PJ, Farmer A, Cannon SB, Woodward J, Kudapa H, Tuteja R, Kumar A, BhanuPrakash A, Mulaosmanovic B, Gujaria N, et al: Large-scale transcriptome analysis in chickpea (Cicer arietinum L.), an orphan legume crop of the semi-arid tropics of Asia and Africa. Plant Biotechnol J 2011, 9:922-931.

29. Tangphatsornruang S, Somta $P$, Uthaipaisanwong $P$, Chanprasert J, Sangsrakru D, Seehalak W, Sommanas W, Tragoonrung S, Srinives P: Characterization of microsatellites and gene contents from genome shotgun sequences of mungbean (Vigna radiata (L.) Wilczek). BMC Plant Biol 2009, 9:137. 
30. Dutta S, Kumawat G, Singh B, Gupta D, Singh S, Dogra V, Gaikwad K Sharma T, Raje R, Bandhopadhya T, et al: Development of genic-SSR markers by deep transcriptome sequencing in pigeonpea [Cajanus cajan (L.) Millspaugh]. BMC Plant Biol 2011, 11:17.

31. Weber APM, Weber KL, Carr K, Wilkerson C, Ohlrogge JB: Sampling the Arabidopsis transcriptome with massively parallel pyrosequencing. Plant Physiol 2007, 144:32-42.

32. Zhang G, Guo G, Hu X, Zhang Y, Li Q, Li R, Zhuang R, Lu Z, He Z, Fang X, et al: Deep RNA sequencing at single base-pair resolution reveals high complexity of the rice transcriptome. Genome Res 2010, 20:646-654.

33. Martin J-F, Pech N, Meglecz E, Ferreira S, Costedoat C, Dubut V, Malausa T, Gilles A: Representativeness of microsatellite distributions in genomes, as revealed by 454 GS-FLX Titanium pyrosequencing. BMC Genomics 2010, 11:560.

34. Hyten D, Song Q, Fickus E, Quigley C, Lim J-S, Choi I-Y, Hwang E-Y, PastorCorrales M, Cregan P: High-throughput SNP discovery and assay development in common bean. BMC Genomics 2010, 11:475.

35. Temsch E, Greilhuber J: Genome size in Arachis duranensis: a critical study. Genome 2001, 44:826-830.

36. Altschul SF, Madden TL, Schaffer AA, Zhang JH, Zhang Z, Miller W, Lipman DJ: Gapped BLAST and PSI-BLAST: a new generation of protein database search programs. Nucleic Acids Res 1997, 25:3389-3402.

37. Seijo JG, Lavia Gl, Fernandez A, Krapovickas A, Ducasse D, Moscone EA: Physical mapping of the $5 \mathrm{~S}$ and 18S-25S rRNA genes by FISH as evidence that Arachis duranensis and A. ipaensis are the wild diploid progenitors of A. hypogaea (Leguminosae). Am J Bot 2004, 91:1294-1303.

38. Zdobnov EM, Apweiler R: InterProScan - an integration platform for the signature-recognition methods in InterPro. Bioinformatics 2001, 17:847848.

39. : PInTFDB a Plant Transcription Factor Database.: ; http://plntfdb.bio.unipotsdam.de/v3.0

40. Meyers BC, Kozik A, Griego A, Kuang H, Michelmore RW: Genome-wide analysis of NBS-LRR-encoding genes in Arabidopsis. The Plant Cell Online 2003, 15:809-834

41. Bertioli DJ, Leal-Bertioli SCM, Lion MB, Santos VL, Pappas G, Cannon SB, Guimaraes PM: A large scale analysis of resistance gene homologues in Arachis. Mol Genet Genomics 2003, 270:34-45.

42. Morgante C, Guimaraes P, Martins A, Araujo A, Leal-Bertioli S, Bertioli D, Brasileiro A: Reference genes for quantitative reverse transcriptionpolymerase chain reaction expression studies in wild and cultivated peanut. BMC Research Notes 2011, 4:339

43. Bennetzen $J$, Ma J, Devos KM: Mechanisms of recent genome size variation in flowering plants. Ann Bot 2005, 95:127-132.

44. Schuler GD: Sequence mapping by electronic PCR. Genome Res 1997 7:541-550.

45. Luo H, Li Y, Sun C, Wu Q, Song J, Sun Y, Steinmetz A, Chen S: Comparison of 454-ESTs from Huperzia serrata and Phlegmariurus carinatus reveals putative genes involved in lycopodium alkaloid biosynthesis and developmental regulation. BMC Plant Biol 2010, 10:209.

46. Blanca J, Canizares J, Roig C, Ziarsolo P, Nuez F, Pico B: Transcriptome characterization and high throughput SSRs and SNPs discovery in Cucurbita pepo (Cucurbitaceae). BMC Genomics 2011, 12:104.

47. Dubey A, Farmer A, Schlueter J, Cannon SB, Abernathy B, Tuteja R, Woodward J, Shah T, Mulasmanovic B, Kudapa H, et al: Defining the transcriptome assembly and its use for genome dynamics and transcriptome profiling studies in pigeonpea (Cajanus cajan L). DNA Res 2011, 18:153-164.

48. Hussain SS, Kayani MA, Amjad M: Transcription factors as tools to engineer enhanced drought stress tolerance in plants. Biotechnol Prog 2011, 27:297-306.

49. Century K, Reuber TL, Ratcliffe OJ: Regulating the regulators: the future prospects for transcription-factor-based agricultural biotechnology products. Plant Physiol 2008, 147:20-29

50. Wang Z, Libault $M$, Joshi $T$, Valliyodan B, Nguyen $H$, Xu D, Stacey G, Cheng J: SoyDB: a knowledge database of soybean transcription factors. BMC Plant Biol 2010, 10:14.

51. Govind G, Vokkaliga ThammeGowda H, Jayaker Kalaiarasi P, lyer D, Muthappa S, Nese S, Makarla U: Identification and functional validation of a unique set of drought induced genes preferentially expressed in response to gradual water stress in peanut. Mol Genet Genomics 2009, 281:591-605.
52. Correa LGG, Riano-Pachon DM, Schrago CG, Vicentini dos Santos R, MuellerRoeber B, Vincentz M: The role of bZip transcription factors in green plant evolution: adaptive features emerging from four founder genes. PLOS One 2008, 3:e2944.

53. Rodriguez-Uribe $L, O^{\prime}$ Connell MA: A root-specific bZIP transcription factor is responsive to water deficit stress in tepary bean (Phaseolus acutifolius) and common bean (P. vulgaris). J Exp Bot 2006, 57:1391-1398.

54. Uno Y, Furihata T, Abe H, Yoshida R, Shinozaki K, Yamaguchi-Shinozaki K Arabidopsis basic leucine zipper transcription factors involved in an abscisic acid-dependent signal transduction pathway under drought and high-salinity conditions. Proc Natl Acad Sci 2000, 97:11632-11637.

55. Zhang Y, Zhang G, Xia N, Wang X-J, Huang L-L, Kang Z-S: Cloning and characterization of a bZIP transcription factor gene in wheat and its expression in response to stripe rust pathogen infection and abiotic stresses. Physiol Mol Plant Pathol 2008, 73:88-94.

56. Singh KB, Foley RC, Onate-Sanchez L: Transcription factors in plant defense and stress responses. Curr Opin Plant Biol 2002, 5:430-436.

57. Yanhui C, Xiaoyuan $Y$, Kun $H$, Meihua L, Jigang L, Zhaofeng G, Zhiqiang L, Yunfei Z, Xiaoxiao W, Xiaoming Q, et al: The MYB transcription factor superfamily of Arabidopsis: expression analysis and phylogenetic comparison with the rice MYB family. Plant Mol Biol 2006, 60:107-124.

58. Dai $X, X u Y, M a ~ Q, X u$ W, Wang $T$, Xue $Y$, Chong $K$ : Overexpression of an R1R2R3 MYB gene, OsMYB3R-2, increases tolerance to freezing, drought, and salt stress in transgenic Arabidopsis. Plant Physiol 2007, 143:17391751

59. Olsen AN, Ernst HA, Leggio LL, Skriver K: NAC transcription factors: structurally distinct, functionally diverse. Trends Plant Sci 2005, 10:79-87.

60. Wang X, Basnayake BMVS, Zhang H, Li G, Li W, Virk N, Mengiste T, Song F: The Arabidopsis ATAF1, a NAC transcription factor, is a negative regulator of defense responses against necrotrophic fungal and bacterial pathogens. Mol Plant Microbe Interact 2009, 22:1227-1238.

61. Le DT, Nishiyama R, Watanabe Y, Mochida K, Yamaguchi-Shinozaki K, Shinozaki K, Tran L-SP: Genome-wide survey and expression analysis of the plant-specific NAC transcription factor family in soybean during development and dehydration stress. DNA Research 2011, :1-14.

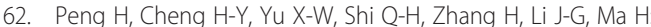
Characterization of a chickpea (Cicer arietinum L.) NAC family gene, CarNAC5, which is both developmentally- and stress-regulated. Plant Physiol Biochem 2009, 47:1037-1045.

63. Yamaguchi-Shinozaki K, Shinozaki K: Transcriptional regulatory networks in cellular responses and tolerance to dehydration and cold stresses. Annu Rev Plant Biol 2006, 57:781-803.

64. Bhatnagar-Mathur P, Devi MJ, Vadez V, Sharma KK: Differential antioxidative responses in transgenic peanut bear no relationship to their superior transpiration efficiency under drought stress. J Plant Physiol 2009, 166:1207-1217

65. Devi MJ, Bhatnagar-Mathur P, Sharma KK, Serraj R, Anwar SY, Vadez V: Relationships between transpiration efficiency and its surrogate traits in the rd29A:DREB1A transgenic lines of groundnut. J Agron Crop Sci 2011, 197:272-283.

66. Zhou JL, Wang XF, Jiao YL, Qin YH, Liu XG, He K, Chen C, Ma LG, Wang J, Xiong $L Z$, et al: Global genome expression analysis of rice in response to drought and high-salinity stresses in shoot, flag leaf, and panicle. Plant Mol Biol 2007, 63:591-608.

67. Zhao L, Hu Y, Chong K, Wang T: ARAG1, an ABA-responsive DREB gene, plays a role in seed germination and drought tolerance of rice. Ann Bot 2010, 105:401-409.

68. Li X-P, Tian A-G, Luo G-Z, Gong Z-Z, Zhang J-S, Chen S-Y: Soybean DREbinding transcription factors that are responsive to abiotic stresses. TAG Theor Appl Genet 2005, 110:1355-1362.

69. Chen M, Wang Q-Y, Cheng X-G, Xu Z-S, Li L-C, Ye X-G, Xia L-Q, Ma Y-Z: GmDREB2, a soybean DRE-binding transcription factor, conferred drought and high-salt tolerance in transgenic plants. Biochem Biophys Res Commun 2007, 353:299-305.

70. Golldack D, Luking I, Yang O: Plant tolerance to drought and salinity: stress regulating transcription factors and their functional significance in the cellular transcriptional network. Plant Cell Rep 2011, 30:1383-1391.

71. Grandbastien MA, Audeon C, Bonnivard E, Casacuberta JM, Chalhoub B, Costa APP, Le QH, Melayah D, Petit M, Poncet C, et al: Stress activation and genomic impact of Tnt1 retrotransposons in Solanaceae. Cytogenet Genome Res 2005, 110:229-241. 
72. Shinozaki K, Yamaguchi-Shinozaki K: Gene networks involved in drought stress response and tolerance. J Exp Bot 2007, 58:221-227.

73. Capy P, Gasperi G, Biemont C, Bazin C: Stress and transposable elements: co-evolution or useful parasites? Heredity 2000, 85:101-106.

74. Jones JDG, Dangl JL: The plant immune system. Nature 2006, 444:323-329.

75. Xiao S, Wang W, Yang $X$, Heine $H$ : Evolution of resistance genes in plants innate immunity of plants, animals, and humans. In Nucleic Acids and Molecular Biology. Volume 21. Berlin: Springer; 2008:1-25.

76. Dangl JL, Jones JDG: Plant pathogens and integrated defence responses to infection. Nature 2001, 411:826-833.

77. Hammond-Kosack KE, Jones JD: Resistance gene-dependent plant defense responses. Plant Cell 1996, 8:1773-1791.

78. Eulgem T, Weigman VJ, Chang H-S, McDowell JM, Holub EB, Glazebrook J Zhu T, Dangl JL: Gene expression signatures from three genetically separable resistance gene signaling pathways for downy mildew resistance. Plant Physiol 2004, 135:1129-1144.

79. Ray JD, Sinclair TR: Stomatal closure of maize hybrids in response to drying soil. Crop Sci 1997, 37:803-807.

80. Papanicolaou A, Stierli R, Ffrench-Constant R, Heckel D: Next generation transcriptomes for next generation genomes using est2assembly. $B M C$ Bioinforma 2009, 10:447.

81. Chevreux B, Pfisterer T, Drescher B, Driesel AJ, Muller WEG, Wetter T, Suhai S: Using the miraEST assembler for reliable and automated mRNA transcript assembly and SNP detection in sequenced ESTs. Genome Res 2004, 14:1147-1159

82. Gotz S, Garcia-Gomez JM, Terol J, Williams TD, Nagaraj SH, Nueda M Robles M, Talon M, Dopazo J, Conesa A: High-throughput functional annotation and data mining with the Blast2GO suite. Nucleic Acids Res 2008, 36:3420-3435.

83. Kolpakov R, Bana G, Kucherov G: mreps: efficient and flexible detection of tandem repeats in DNA. Nucleic Acids Res 2003, 31:3672-3678.

84. Untergasser A, Nijveen H, Rao X, Bisseling T, Geurts R, Leunissen JAM: Primer3Plus, an enhanced web interface to Primer3. Nucleic Acids Res 2007, 35:W71-W74.

85. Primer Match. http://edwardslab.bmcb.georgetown.edu/software/ primer_match.html.

doi:10.1186/1471-2164-13-387

Cite this article as: Guimarães et al:: Global transcriptome analysis of two wild relatives of peanut under drought and fungi infection. BMC Genomics 2012 13:387.

\section{Submit your next manuscript to BioMed Central and take full advantage of:}

- Convenient online submission

- Thorough peer review

- No space constraints or color figure charges

- Immediate publication on acceptance

- Inclusion in PubMed, CAS, Scopus and Google Scholar

- Research which is freely available for redistribution 